\title{
Reattachment of the Osteotomized Greater Trochanter in Hip Surgery Using an Ultrahigh Molecular Weight Polyethylene Fiber Cable: A Multi-Institutional Study
}

\author{
Seiya Jingushi ${ }^{1 *}$, Tsutomu Kawano ${ }^{1}$, Hirokazu Iida ${ }^{2}$, Kenichi $\mathrm{Oe}^{2}$, Kenji Ohzono ${ }^{3}$, \\ Yoshihide Nakamura ${ }^{4}$, Makoto Osaki ${ }^{5}$, Hidetsugu Ohara ${ }^{6}$, Seung Bak Lee ${ }^{7}$, Toshihiko Hara ${ }^{8}$, \\ Naohide Tomita9
}

${ }^{1}$ Department of Orthopaedic Surgery, Kyushu Rosai Hospital, Kitakyushu, Japan; ${ }^{2}$ Department of Orthopaedic Surgery, Kansai Medical University, Hirakata, Japan; ${ }^{3}$ Department of Orthopaedic Surgery, Kansai Rosai Hospital, Amagasaki, Japan; ${ }^{4}$ Department of Orthopaedic Surgery, Hirosaki University Hospital, Hirosaki, Japan; ${ }^{5}$ Department of Orthopaedic Surgery, Nagasaki University Graduate School of Medical Science, Nagasaki, Japan; ${ }^{6}$ Department of Orthopaedic Surgery, Osaka Medical College, Takatsuki, Japan; ${ }^{7}$ Department of Rehabilitation, Toyonaka Municipal Hospital, Toyonaka, Japan; ${ }^{8}$ Department of Orthopaedic Surgery, Kyushu Kosei Nenkin Hospital, Kitakyushu, Japan; ${ }^{9}$ Bioengineering Laboratory, Graduate School of Engineering, Kyoto University, Kyoto, Japan.

Email: ${ }^{*}$ jingushi.orth@kyushuh.rofuku.go.jp

Received September $3^{\text {rd }}, 2013$; revised October $5^{\text {th }}, 2013$; accepted October $15^{\text {th }}, 2013$

Copyright (C) 2013 Seiya Jingushi et al. This is an open access article distributed under the Creative Commons Attribution License, which permits unrestricted use, distribution, and reproduction in any medium, provided the original work is properly cited.

\begin{abstract}
The purpose of this multicenter study was to evaluate the clinical performance of an ultrahigh molecular weight polyethylene (UHMWPE) fiber cable for re-attachment of the osteotomized greater trochanter in hip surgery. Included in the study were 85 hips that had undergone surgery with greater trochanter osteotomy, including 50 hip arthroplasty procedures and 35 hip osteotomies. The osteotomized greater trochanter was reattached using one or more UHMWPE fiber cables. The bone union and displacement of the greater trochanter were assessed in radiographs for up to 12 months after surgery. Non-union of the osteotomy site occurred in $4.7 \%$ of the cases. In approximately $90 \%$ of the cases, displacement was less than $2 \mathrm{~mm}$ at up to 12 months after surgery. The UHMWPE fiber cable was a good biomaterial for reattaching the osteotomized greater trochanter and may also be an option for osteosynthesis procedures.
\end{abstract}

Keywords: Ultrahigh Molecular Weight Polyethylene Fiber Cable; Biomaterials; Osteosynthesis; Greater Trochanter Osteotomy; Hip Operations; Arthroplasty

\section{Introduction}

In hip operations, techniques for how to fix a fractured or osteotomized greater trochanter may produce challenges. An encircling metal fixation device, such as a steel wire or titanium cable, has long been used in the internal fixation of fractures and the re-attachment of the osteotomized greater trochanter in total hip arthroplasty (THA), revision THA, or osteotomy. However, these implants have associated problems, including breakage of fixation materials, trochanteric nonunion, and bursitis. The breakage rate following these procedures has been reported to be $0.4 \%-28 \%$ for steel wire [1-5] and $3.1 \%-43 \%$ for wire cable [6-9]. Wire failure due to low-cycle fatigue remains the most common problem. Cable fraying and

\footnotetext{
*Corresponding author.
}

fragmentation have been reported to develop in $50 \%$ of patients, and the use of cables has limited effectiveness in reducing the incidence of trochanteric nonunion $[6,7]$. Furthermore, Oh et al. [10] noted that a $1 \%$ notch has been reported to be enough to reduce the fatigue resistance of the wire by $63 \%$. Trochanteric non-union rates of $0.4 \%-21 \%$ for steel wire [1-5] and $1.5 \%-38 \%$ for wire cable have been reported [6-9]. Trochanteric nonunion may lead to pain, limp, and postoperative dislocation. Additionally, these metal implants could cause localized bursitis. The need for materials with greater strength that can resist both fatigue and static tensile forces, as well as reduce abrasiveness, has prompted the development of new biomaterials for use as orthopedic reconstructive appliances.

Ultrahigh molecular weight polyethylene (UHMWPE) 
fiber cable is a soft, flexible material created in the form of a tape. It is used to bind a metal rod to the bone in spinal surgeries due to its strong fixation ability. Dickman et al. reported that UHMWPE fiber cables are superior in static ultimate tensile strength, fatigue strength, conformance, and abrasion as compared with titanium cable, steel cable, or steel wire in spinal fusion surgeries [11]. Murakami et al. reported that UHMWPE fiber cables perform better than steel wire or titanium cable in laminar cut-through and biomechanical stiffness tests [12]. Our preliminary experiment showed that the practical strength of the UHMWPE fiber cable was comparable to that of wire cable, but that the fatigue strength of the UHMWPE cable was significantly higher [13]. Our animal model experiment showed that the UHMWPE fiber cable was as easily removed as the soft wire cable, and that it caused minimal biological reactivity with the surrounding tissue [13]. Due to the UHMWPE fiber cable design (soft, wide, flat tape), it is useful for binding and causes less local stress with little possibility of cutting into bone, unlike the soft wire or titanium cable. This design may ameliorate the "cheese wire effect" that can occur during fixation of fragile bones in elderly osteoporotic patients. We hypothesized that a UHMWPE fiber cable would be an excellent material for use in osteosynthesis for the osteotomized greater trochanter, as well as for binding a metal rod to bone in spinal surgical procedures. The purpose of this multicenter study was to evaluate the clinical performance of a UHMWPE fiber cable in re-attachment of the osteotomized greater trochanter in hip operations.

\section{Patients and Methods}

Patients who had hip operations with a greater trochanter osteotomy at one of the eight hospitals (Kyushu Rosai Hospital, Kitakyushu, Japan; Kansai Medical University, Hirakata, Japan; Kansai Rosai Hospital, Osaka, Japan; Hirosaki University Hospital, Hirosaki, Japan; Nagasaki University Hospital, Nagasaki, Japan; Osaka Medical College Hospital, Takatsuki, Japan; Toyonaka Municipal Hospital, Toyonaka, Japan; and the Kyushu Kosei Nenkin Hospital, Kitakyuushu, Japan) were included in the study. In the institutions, the UHMWPE fiber cable was used in hip operations with a greater trochanter osteotomy. Following institutional review board approval at each hospital, data were collected from the patient records.

Eighty-five hips (of 14 male and 71 female patients) were included in the evaluation of the UHMWPE fiber cable. Fifty hip arthroplasties and 35 hip osteotomies were performed. Patient characteristics are shown in the Table 1. Patients undergoing osteotomy were younger and taller than those undergoing arthroplasty procedures.
Forty-eight of the hips that needed arthroplasty had primary total hip arthroplasty and two had revision procedures. Of the hips undergoing osteotomy, 27 had pelvic osteotomy with coverage of the articular cartilage [14], four had Chiari pelivic osteotomy [15], and four had transtrochanteric rotational osteotomy [16] procedures performed.

Osteotomy of the greater trochanter was classified into two types depending on the continuity between abductor and vastus lateralis muscle (Table 2). More than half of the total number of cases $(52.9 \%, 45 / 85$ patients) showed maintained continuity after the osteotomy. In most of the hips undergoing arthroplasty $(86 \%, 43 / 50$ patients), continuity was maintained according to Dall's approach [17]. In contrast, continuity was maintained in only $6 \%(2 / 35$ patients) of the hips undergoing osteotomy.

In all the cases, the osteotomized greater trochanter was reattached using one or more UHMWPE fiber cable (NESPLON Cable System, Alfresa Pharma Corporation, Osaka, Japan). Cables of $3 \mathrm{~mm}$ or $5 \mathrm{~mm}$ width were used. Fixation status (Table 2) varied by institution. The cables

Table 1. Patient characteristics.

\begin{tabular}{cccc}
\hline Variable & $\begin{array}{c}\text { Osteotomy } \\
(\mathrm{n}=35)\end{array}$ & $\begin{array}{c}\text { Arthroplasty } \\
(\mathrm{n}=50)\end{array}$ & $p$ value \\
\hline Sex (n), Male/Female & $7 / 28$ & $7 / 43$ & $0.556^{\mathrm{a}}$ \\
Age (years), mean \pm SD & $36.5 \pm 12.4$ & $64.6 \pm 10.0$ & $<0.001^{\mathrm{b}}$ \\
Height (cm), mean \pm SD & $158.9 \pm 7.5$ & $152.2 \pm 9.0$ & $<0.001^{\mathrm{b}}$ \\
Weight (kg), mean \pm SD & $57.1 \pm 12.8$ & $55.3 \pm 10.1$ & $0.449^{\mathrm{b}}$ \\
$\begin{array}{c}\text { Body mass index } \\
\left(\mathrm{kg} / \mathrm{m}^{2}\right), \text { mean } \pm \mathrm{SD}\end{array}$ & $22.6 \pm 4.5$ & $23.7 \pm 3.2$ & $0.162^{\mathrm{b}}$ \\
$\begin{array}{c}\text { Hip disease } \\
\text { Osteoarthritis of the hip }\end{array}$ & 31 & & $0.026^{\mathrm{a}}$ \\
$\begin{array}{c}\text { Osteonecrosis of the } \\
\text { femoral head }\end{array}$ & 4 & 0 & \\
Revisions & 0 & 2 & \\
\hline
\end{tabular}

${ }^{\mathrm{a}}$ Fischer's exact test, ${ }^{\mathrm{b}}$ Two-sample t-test.

Table 2. Fixation conditions of the osteotomized greater trochanter.

\begin{tabular}{cccc}
\hline Variable & $\begin{array}{c}\text { Osteotomy } \\
(\mathrm{N}=35)\end{array}$ & $\begin{array}{c}\text { Arthroplasty } \\
(\mathrm{N}=50)\end{array}$ & $p$ value $^{*}$ \\
\hline $\begin{array}{c}\text { Maintenance of continuity } \\
\text { between abductor and } \\
\text { vastus lateralis (n/N) }\end{array}$ & $5.7 \%(2 / 35)$ & $86.0 \%(43 / 50)$ & $<0.001$ \\
Around the bone (n/N) & $8.6 \%(3 / 35)$ & $96.0 \%(48 / 50)$ & $<0.001$ \\
$\begin{array}{c}\text { Through the bone (n/N) } \\
\begin{array}{c}\text { Combined fixation } \\
\text { materials (n), Y/N }\end{array}\end{array}$ & $22.9 \%(8 / 35)$ & $66.0 \%(33 / 50)$ & $<0.001$ \\
\hline
\end{tabular}

"Fisher's exact test; $\mathrm{N}=$ total number of patient hips, $\mathrm{n}=$ number of patient hips fitting this variable. 
were tightened circumferentially around the bone or through the bones after drilling holes (diameter of holes: $2-3 \mathrm{~mm}$ ). In most of the hips undergoing arthroplasty $(96 \%)$, the cable was tightened around the bone (Figure 1(b)). In contrast, in most of the undergoing osteotomy (91\%), the cable was passing through the bone of the greater trochanter and the proximal femur for the fixation (Figure 1(a)). Two cables were used for 24 of the hips undergoing osteotomy, while one cable was used along with additional fixation materials (one cortical screw or one soft wire) for eight hips. In contrast, one $(64 \%, 32 / 50)$ or two cable $(32 \%, 16 / 50)$ was used in most of the hips undergoing arthroplasty. None of the hips had additional fixation materials. The average tension strength of the osteotomy and arthroplasty hips was $21 \pm 3.5 \mathrm{~kg}$ and 30 $\pm 2.0 \mathrm{~kg}$, respectively. The cable tightening tension for the arthroplasty hips was significantly greater than that for the osteotomy hips.

The representative fixation status of the osteotomized greater trochanter in the osteotomy or arthroplasty hips is shown in Figure 1. In the osteotomy hips, the whole greater trochanter was osteotomized without continuity between the abductor and vastus lateralis muscles. Two cables were passing through the greater trochanter fragment and the proximal part of the femur, and were tightened to tension strength of approximately $20 \mathrm{~kg}$. In the arthroplasty hip, the anterior part of the greater trochanter was osteotomized with continuity between the abductor and vastus lateralis muscles. One cable was tightening

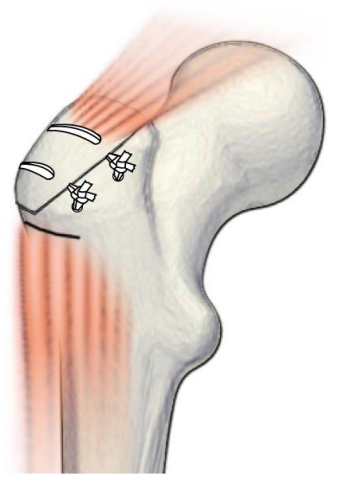

(a)

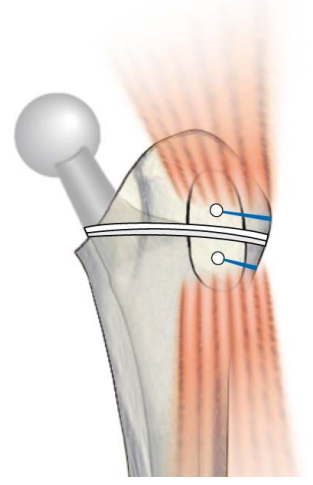

(b)
Figure 1. The representative fixation status of the osteotomized greater trochanter in the osteotomy (a) or arthroplasty hips (b). In the osteotomy hip, the total greater trochanter was osteotomized without continuity between the abductor muscle and the vastus lateralis, and it was reattached using two cables running through the bone tissue. In the arthroplasty hip, the anterior part of the greater trochanter was osteotomized with continuity between the abductor muscle and the vastus lateralis, and it was reattached using one or more cables around the bone and the stem neck. over the greater trochanter fragment and the femoral implant neck to tension strength of approximately $30 \mathrm{~kg}$. The cable was looped by tying with a double loop-sliding knot technique using a tensioning device (Alfresa Pharma) (Figure 2).

The bone union and displacement of the osteotomized greater trochanter were examined in two views of radiographs taken 3, 6, and 12 months after surgery, compareing the images with those obtained just after surgery. The bone union score was assessed as one of four grades: $0=$ no change; 1 = bridging callus; $2=$ trabecular or cortical bone continuity; or 3 = trabecular or cortical bone continuity in both views. Displacement of the osteotomized greater trochanter was assessed as one of four grades: $0=$ $\geq 10 \mathrm{~mm} ; 1=\geq 5 \mathrm{~mm}$ to $<10 \mathrm{~mm} ; 2=\geq 2 \mathrm{~mm}$ to $<5$ $\mathrm{mm}$; or $3=<2 \mathrm{~mm}$.

Patient characteristics (except for sex) were analyzed using a two-sample t-test. Sex and fixation condition were analyzed using Fisher's exact test. Bone union score and displacement score were analyzed using a two sample t-test. Proportions of the bone union score and displacement score were analyzed using Fisher's exact test. Values with a p-value of less than 0.05 were regarded as statistically significant. Results are presented as means \pm standard deviation.

\section{Results}

The average bone union score was less than 2 at 3 months after surgery in both the osteotomy and arthroplasty hips (Table 3), with no significant difference between the group values. At 6 months after surgery, bone union scores were significantly lower in the osteotomy hips than that in the arthroplasty hips. By 12 months after surgery, the mean score was greater than 2.5 in both operative groups. At 3 months after surgery, the proportion of osteotomy and arthroplasty hips in which the bone union score was 2 or 3 was $32 \%$ and $52 \%$, respectively (Figure 3). At 6 months after surgery, the proportion of osteotomy hips at a score of 2 or $3(62 \%)$ was significantly lower than that of the arthroplasty hips $(96 \%)(\mathrm{p}<$ $0.001)$. Twelve months after the operation, most hips in

Table 3. Bone union score of the osteotomized greater trochanter at each postoperative interval.

\begin{tabular}{cccccccc}
\hline & \multicolumn{6}{c}{ Postoperative interval } \\
\cline { 2 - 8 } & \multicolumn{3}{c}{3 months } & & 6 months & \multicolumn{2}{c}{12 months } \\
\cline { 2 - 8 } & $\mathrm{n}$ & mean $\pm \mathrm{SD}$ & $\mathrm{n}$ & mean $\pm \mathrm{SD}$ & $\mathrm{n}$ & mean $\pm \mathrm{SD}$ \\
\hline Total & 84 & $1.4 \pm 1.0$ & 84 & $2.3 \pm 0.9$ & 78 & $2.7 \pm 0.7$ \\
Osteotomy & 34 & $1.2 \pm 1.1$ & 34 & $2.0 \pm 1.0^{*}$ & 31 & $2.5 \pm 0.7$ \\
Arthroplasty & 50 & $1.5 \pm 0.9$ & 50 & $2.5 \pm 0.7$ & 47 & $2.8 \pm 0.6$ \\
\hline${ }^{*} \mathrm{p}<0.01$, two sample t-test vs. arthroplasty. & & & &
\end{tabular}

${ }^{*} \mathrm{p}<0.01$, two sample t-test vs. arthroplasty. 


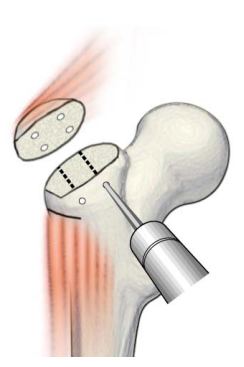

(a)

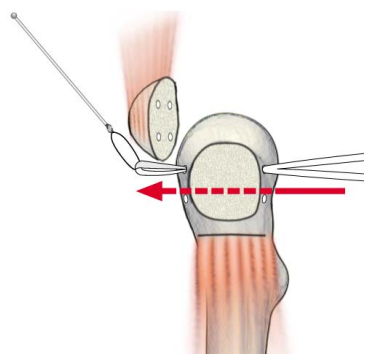

(b)

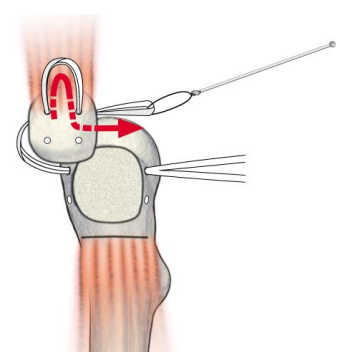

(c)

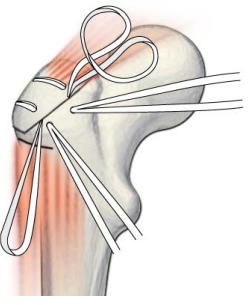

(d)

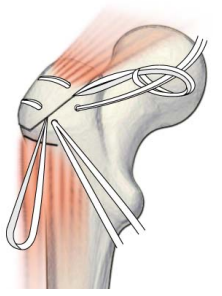

(e)

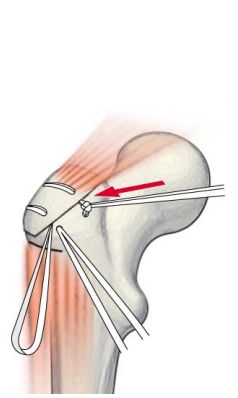

(f)

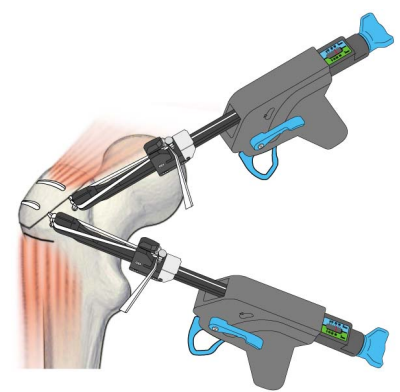

(g)

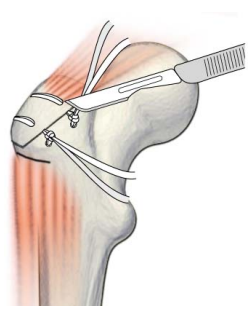

(h)

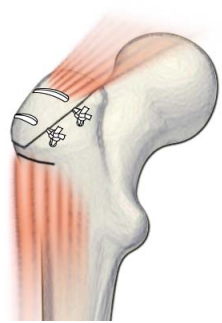

(i)

Figure 2. The representative method for reattaching the osteotomized greater trochanter in the osteotomy hip using the cables. a-c: Four holes were drilled in the greater trochanter fragment, with two holes in the proximal part of the femur paralleling the osteotomy plane. The cable was passed through the hole in the proximal femur and two holes of the fragment. d-g: The cable was looped by tying with double loop-sliding knot technique using the tensioning device. $h$ and i: The remnant cable was cut off using a scalpel.

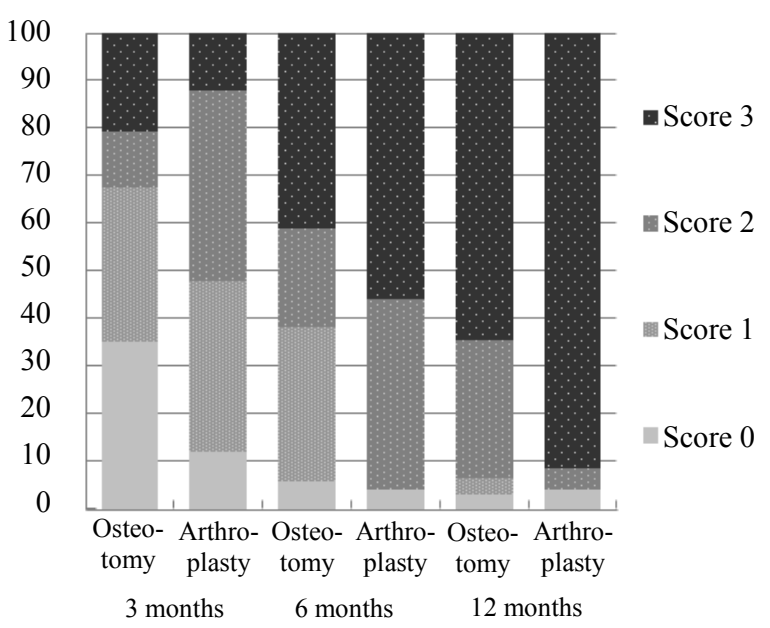

Figure 3. The proportion of the osteotomy and arthroplasty hips, in which the bone union score was 0 to 3 , where $0=$ no changes, 1 = bridging callus, 2 = trabecular or cortical bone continuity, and 3 = trabecular or bone continuity in both of two views.

both of the groups reached a score of 2 or 3 , indicating that there was bone continuity in at least one radiograph view. The proportion of the osteotomy hips at a bone union score of $3(64.5 \%)$ was lower than seen in the arthroplasty hips $(91.5 \%)(\mathrm{p}=0.006)$.

The average displacement score of all hips was approximately 3 at any time after the operation, and there were no significant differences between the osteotomy and the arthroplasty hip findings (Table 4). More than $90 \%$ of the osteotomy and arthroplasty hips had scores of 2 or 3 at any time after the operation (Figure 4). One year after the surgery, the proportions of the osteotomy and arthroplasty hips with displacement scores of 3 were $87.1 \%$ and $89.4 \%$, respectively.

There were four non-union cases $(4.7 \%)$, in which bone union score was less than 2 at 12 months after the operation. These low scores were reported for two osteotomy hips (5.7\%) and two arthroplasty hips (4.0\%). In one of the osteotomy hips, re-operation to fix the greater trochanter was necessary.

\section{Discussion}

Non-union of the osteotomy site occurred in 4.7\% (4 hips) of the cases studied. The previously reported rate of nonunion was $0.4 \%$ to $21 \%$ for procedures using a soft wire [1-5] and $1.5 \%$ to $38 \%$ for wire cable fixation [6-9]. We found that the new UHMEPE cable had relatively good clinical performance in reattaching the osteotomized greater trochanter.

The bone union score of the osteotomy hips was slightly less than that of the arthroplasty hips at 6 or 12 months after surgery, but this may be due to the differences in the osteotomy procedure of the greater trochanter. Most hips undergoing arthroplasty had continuity be- 
Table 4. Displacement score of the osteotomized greater trochanter at each postoperative interval.

\begin{tabular}{|c|c|c|c|c|c|c|}
\hline & \multicolumn{6}{|c|}{ Postoperative intervals } \\
\hline & \multicolumn{2}{|r|}{3 months } & \multicolumn{2}{|c|}{6 months } & \multicolumn{2}{|c|}{12 months } \\
\hline & $\mathrm{n}$ & mean $\pm \mathrm{SD}$ & $\mathrm{n}$ & mean $\pm \mathrm{SD}$ & $\mathrm{n}$ & mean $\pm \mathrm{SD}$ \\
\hline Total & 84 & $2.8 \pm 0.7$ & 84 & $2.8 \pm 0.7$ & 78 & $2.8 \pm 0.6$ \\
\hline Osteotomy & 34 & $2.7 \pm 0.7$ & 34 & $2.8 \pm 0.7$ & 31 & $2.8 \pm 0.5$ \\
\hline Arthroplasty & 50 & $2.8 \pm 0.7$ & 50 & $2.8 \pm 0.7$ & 47 & $2.8 \pm 0.7$ \\
\hline
\end{tabular}

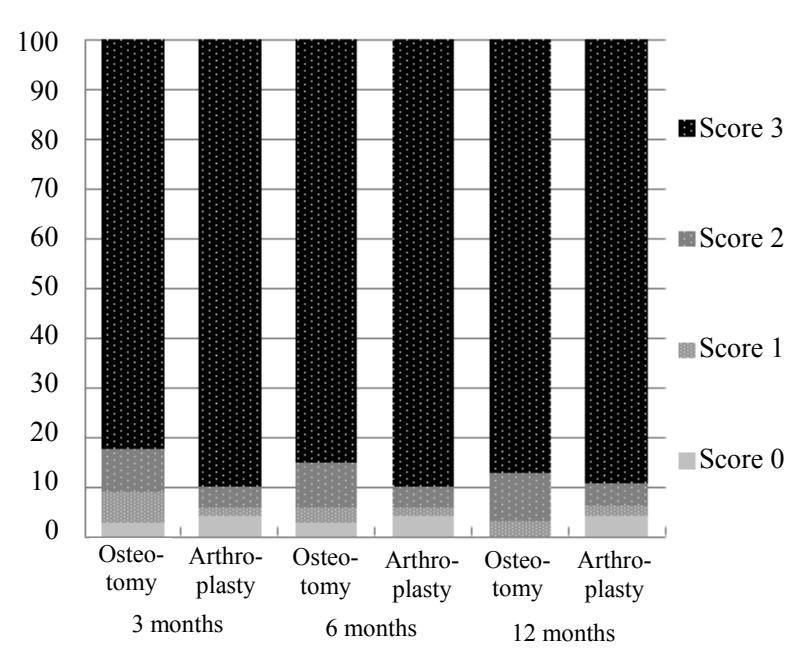

Figure 4. The proportion of the osteotomy and arthroplasty hips, in which the displacement score was 0 to 3 , where $0=$ more than $10 \mathrm{~mm}, 1=\geq 5 \mathrm{~mm}$ to $<10 \mathrm{~mm}, 2=\geq 2 \mathrm{~mm}$ to $<$ $5 \mathrm{~mm}$, and $3=<2 \mathrm{~mm}$.

tween the abductor and vastus lateralis muscle, while most hips undergoing osteotomy did not. The greater trochanter fragment in the arthroplasty hips was more stable than noted in the osteotomy hips. Differences in the size of the greater trochanter fragment might also have influenced the bone union score.

One osteotomy hip had a re-operation due to the displacement of the osteotomized greater trochanter; one cable with a screw was used to re-attach it. In the osteotomy hips, the bone union score of the hips using two cables was lower than that of the hips using one cable and one other material like a screw (data not shown). These inconsistent results may suggest that there was another important factor for obtaining the union other than the biomaterials used. Many doctors who participated in this study pointed out a pitfall when tightening the UHMEPE cable: One tightening action using the tensioning device was not usually sufficient to fix the greater trochanter fragment tightly. Since this cable was a soft, flexible material, there was a time delay between the action of tightening the cable using the tensioning device and the actual tightness at the binding site. In order to obtain sufficient tightness at the binding site, several tightening actions were need. Since the tightening strength will be shown in a display window of the tensioning device, the operator should tighten the cable several times, until the strength reaches and stays at approximately 20 to $30 \mathrm{~kg}$.

It is interesting that the displacement score did not change until the last assessment time at 12 months after the operation in all hips. These findings indicate the capability of the cable to maintain the tightened condition. There were no differences between the displacement scores of the arthroplasty and osteotomy hips; the maintained tight fixation may overcome stability differences at the osteotomy site between the arthroplasty and osteotomy hips. These advantages are likely based on the practical strength and fatigue strength of the cable. Our previous preliminary study showed that the practical strength was approximately 1.5 or 2 times greater when compared with that of a wire cable or soft wire, respectively. The preliminary study also showed that the fatigue strength of the UHMEPE cable was more than 500 or 5000 times greater than seen with titanium cable or soft wire, respectively [13].

The cables have been removed easily from several patients examined in this study (Figure 5). In our previous animal experiments, the removability of the cable was compared with a soft wire or a wire cable [13]. The UHMWPE fiber cable was as easy to remove as a soft wire and was easier than removing a titanium cable in this surgical situation. Our histological study in the animal [13] showed that there was no bone formation in the fibers of the cable and very little reaction with the adjacent soft tissue, supporting our claim that the UHMWPE fiber cable is a user-friendly material.

This study had several limitations. First, all the cases that were examined in this study were the first series for each institution in the use this new biomaterial. During this study, we found a pitfall in tightening this new material of the UHMWPE fiber cable, as noted above. The union rate of the greater trochanter might be improved when the cable was tightened, while taking care to tighten to adequate tension strength. Secondly, there was a variety of ways to complete fixation of the osteotomized greater trochanter and ways to reattach it. This variation of techniques made it difficult for us to propose the best method to reattach the trochanter using this cable, although the clinical outcomes were relatively good using any of the methods we used. Additionally, assessments were carried out at each institution, rather than by a central assessor for all patient outcome evaluations; there might be inter-observer differences in the scoring.

\section{Conclusion}

In conclusion, the UHMWPE fiber cable is a good biomaterial option for use in reattaching the osteotomized 


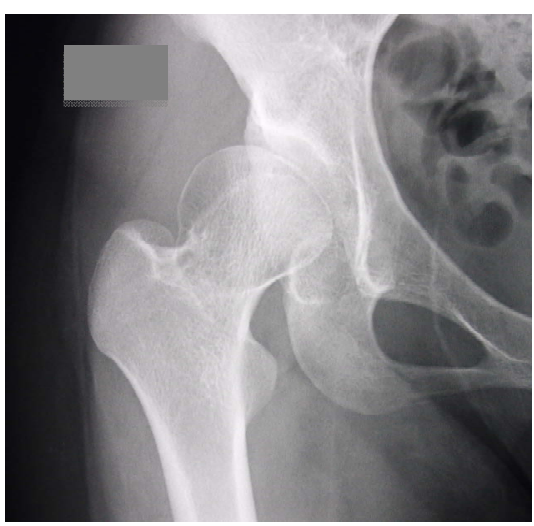

(a)

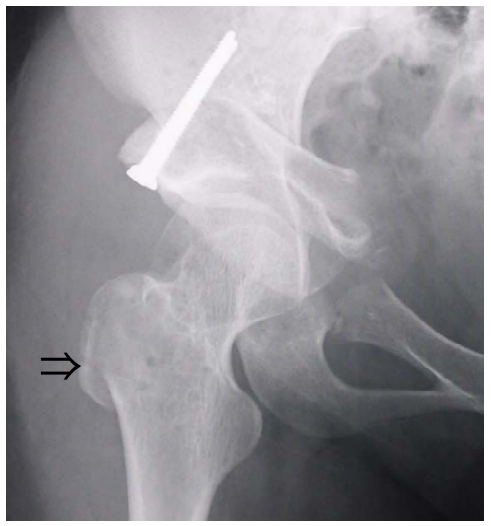

(b)

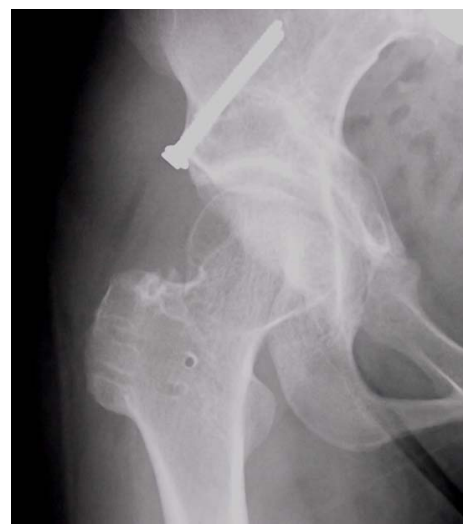

(c)

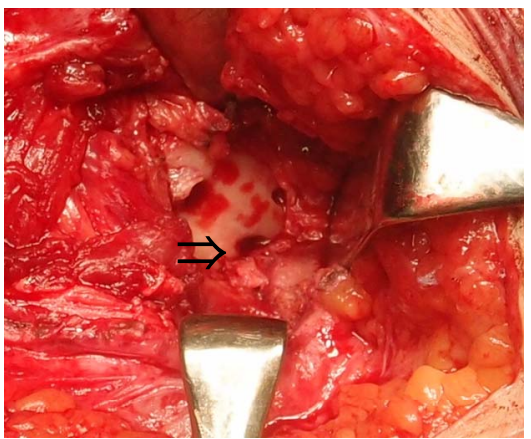

(d)

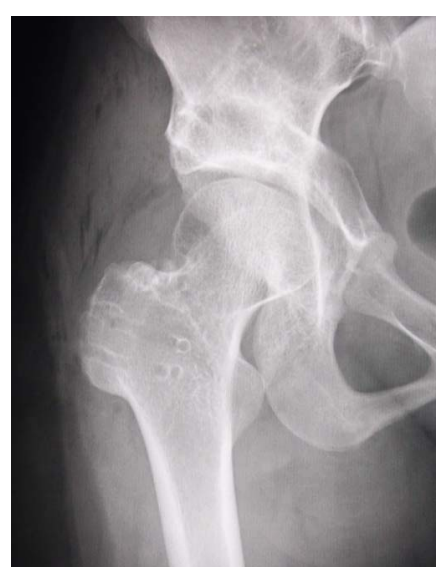

(e)

Figure 5. A representative case of the osteotomy hip. a: Before the osteotomy. b: Just after the osteotomy. The arrowhead points to the cable hole (the cable is not visible). c: Eighteen months after the osteotomy. The greater trochanter is united. Two holes drilled for the cables are observed. d: The hole (the arrow) of the proximal femur after removal of the cable. e: After the removal operation.

greater trochanter. We hypothesize that this cable might be also a good biomaterial for osteosynthesis in many fractured bones.

\section{Acknowledgements}

This study was supported by a grant from the Alfresa Pharma Corporation. We would like to appreciate Drs. Naofumi Okamoto (Department of Orthopaedic Surgery, Kansai Medical University, Hirakata, Japan), Kengo Yamamoto (Department of Orthopaedic Surgery, Kansai Rosai Hospital, Amagasaki, Japan), Hisakata Goto (Department of Orthopaedic Surgery, Nagasaki University Graduate School of Medical Science, Nagasaki, Japan), Tetsuro Nakamura (Department of Orthopaedic Surgery, Kyushu Kosei Nenkin Hospital, Kitakyushu, Japan) for their great help for this study.

\section{REFERENCES}

[1] H. C. Amstutz and S. Maki, "Complications of Trochan- teric Osteotomy in Total Hip Replacement," The Journal of Bone \& Joint Surgery, Vol. 60, No. 2, 1978, pp. 214216.

[2] N. S. Eftekhar, "Total Hip Arthroplasty," CV Mosby, St. Louis, 1993, pp. 16-61.

[3] N. F. Jensen and W. H. Harris, "A System for Trochanteric Osteotomy and Reattachment for Total Hip Arthroplasty with a Ninety-Nine Percent Union Rate," Clinical Orthopaedics and Related Research, Vol. 208, 1986, pp. 174-181.

[4] R. W. Nutton and R. G. Checketts, "The Effects of Trochanteric Osteotomy on Abductor Power," The Journal of Bone \& Joint Surgery of British, Vol. 66, No. 2, 1984, pp. 180-183.

[5] B. M. Wroblewski and P. Shelley, "Reattachment of the Greater Trochanter after Hip Replacement," The Journal of Bone \& Joint Surgery of British, Vol. 67, No. 5, 1985, pp. 736-740.

[6] S. S. Kelley and R. C. Johnston, "Debris from CobaltChrome Cable May Cause Acetabular Loosening," Clinical Orthopaedics and Related Research, Vol. 285, 1992, pp. 140-146. 
[7] C. D. Silverton, J. J. Jacobs, A. G. Rosenberg, et al., "Complications of a Cable Grip System," Journal of Arthroplasty, Vol. 11, No. 4, 1996, pp. 400-404.

http://dx.doi.org/10.1016/S0883-5403(96)80029-5

[8] D. M. Dall and A. W. Miles, "Reattachment of the Greater Trochanter. The Use of the Trochanter Cable-Grip System," The Journal of Bone \& Joint Surgery of British, Vol. 65, No. 1, 1983, pp. 55-59.

[9] M. A. Ritter, L. E. Eizember, E. M. Keating, et al., "Trochanteric Fixation by Cable Grip in Hip Replacement," The Journal of Bone \& Joint Surgery of British, Vol. 73, No. 4, 1991, pp. 580-581.

[10] I. Oh, T. W. Sander and R. W. Treharne, "The Fatigue Resistance of Orthopaedic Wire," Clinical Orthopaedics and Related Research, Vol. 192, 1985, pp. 228-236.

[11] C. A. Dickman, S. M. Papadopoulos, N. R. Crawford, et al., "Comparative Mechanical Properties of Spinal Cable and Wire Fixation Systems," Spine, Vol. 22, No. 6, 1997, pp. 596-604. http://dx.doi.org/10.1097/00007632-199703150-00004

[12] H. Murakami, K. Yamazaki, E. S. Attallah-Wasif, et al., "A Biomechanical Study of 3 Different Types of Sublaminar Wire Used for Constructs in the Thoracic Spine,"
Journal of Spinal Disorders \& Techniques, Vol. 19, 2006, pp. 442-446. http://dx.doi.org/10.1097/00024720-200608000-00012

[13] K. Oe, S. Jingushi, H. Iida, et al., "Evaluation of the Clinical Performance of Ultrahigh Molecular Weight Polyethylene Fiber Cable Suing a Dog Osteosynthesis Model," Bio-Medical Materials and Engineering (in press).

[14] A. Matsuo, S. Jingushi, Y. Nakashima, et al., "Transposition Osteotomy of the Acetabulum for Advanced-Stage Osteoarthritis of the Hips," Journal of Orthopaedic Science, Vol. 14, No. 3, 2009, pp. 266-273. http://dx.doi.org/10.1007/s00776-009-1327-x

[15] K. Chiari, "Medial Displacement Osteotomy of the Pelvis," Clinical Orthopaedics, Vol. 98, 1974, pp. 55-71. http://dx.doi.org/10.1097/00003086-197401000-00008

[16] Y. Sugioka, I. Katsuki and T. Hotokebuchi, "Transtrochanteric Rotational Osteotomy of the Femoral Head for the Treatment of Osteonecrosis-Follow-Up Statistics," Clinical Orthopaedics, Vol. 169, 1982, pp. 115-126.

[17] D. Dall, "Exposure of the Hip by Anterior Osteotomy of the Greater Trochanter. A Modified Anterolateral Approach," The Journal of Bone \& Joint Surgery, Vol. 68B, No. 3, 1986, pp. 382-386. 